Cahiers $d u$ MONDE RUSSE

\section{Cahiers du monde russe}

Russie - Empire russe - Union soviétique et États indépendants

$61 / 3-4 \mid 2020$

Écritures visuelles, sonores et textuelles de la justice

\title{
Katherine ZUBOVICH, Moscow Monumental. Soviet Skyscrapers and Urban Life in Stalin's Capital
}

\section{Clarence Hatton-Proulx}

\section{OpenEdition \\ Journals}

Édition électronique

URL : https://journals.openedition.org/monderusse/12253

DOI : $10.4000 /$ monderusse. 12253

ISSN : $1777-5388$

Éditeur

Éditions de l'EHESS

Édition imprimée

Date de publication : 1 juillet 2020

Pagination : $561-562$

ISBN : 978-2-7132-2832-2

ISSN : $1252-6576$

Référence électronique

Clarence Hatton-Proulx, "Katherine ZUBOVICH, Moscow Monumental. Soviet Skyscrapers and Urban Life in Stalin's Capital », Cahiers du monde russe [En ligne], 61/3-4 | 2020, mis en ligne le 01 juillet 2020,

consulté le 08 septembre 2022. URL : http://journals.openedition.org/monderusse/12253 ; DOI :

https://doi.org/10.4000/monderusse. 12253 


\section{Katherine ZUBOVICH}

\section{Moscow Monumental}

\section{Soviet Skyscrapers and Urban Life in Stalin's Capital}

Princeton : Princeton University Press, 2021, 288 p.

L'étude de l'architecture moscovite pendant la période stalinienne s'arrête bien souvent au palais des Soviets. Ce projet de construction du plus haut gratte-ciel du monde, qui a suscité des propositions de grands architectes occidentaux et soviétiques pour finalement ne jamais être complètement construit, ne saurait pourtant épuiser la richesse du sujet. Le livre de Katherine Zubovich, s'il consacre un chapitre à ce palais, va bien au-delà. Il étudie la planification et la construction des sept gratte-ciels staliniens de Moscou (vysotki, aussi surnommés les Sept Sœurs) entre les années 1930 et les années 1950, offrant du même coup un regard plus large sur la vie urbaine dans la capitale de l'Union soviétique.

Les apports historiographiques de ce livre sont nombreux. Autour de l'épisode du palais des Soviets, Zubovich, dans la veine du travail de Jean-Louis Cohen sur l'américanisme russe, démontre à quel point les architectes et ingénieurs soviétiques sont allés chercher une expertise technique en Occident, particulièrement aux États-Unis, par exemple pour l'édification des fondations. La frustration d'un Le Corbusier, qui a fait suite au choix du style néoclassique pour le palais au détriment du modernisme architectural, n'a pas empêché cette collaboration transnationale dans les années 1930. Les architectes du projet se sont aussi rendus en Italie afin de s'inspirer de l'architecture classique de Pompéi et d'Herculanum, mélangeant les méthodes de construction industrielles américaines et les lignes romaines.

À contre-courant de l'emphase démesurée accordée aux plans et aux projets utopiques par l'histoire de l'architecture, Zubovich s'attache plutôt à comprendre les conséquences matérielles réelles des constructions monumentales étudiées. Celles-ci incluent notamment la démolition de quartiers entiers et le déplacement de leurs habitants. Ainsi, le quartier populaire de Zarjad'e près du Kremlin est rasé pour faire place à un gratte-ciel qui ne sera finalement jamais construit. Ses habitants, non compensés monétairement, sont relogés dans des appartements de surface similaire, mais dans des banlieues lointaines. S'ils ne semblent pas mécontents de quitter leurs logements extrêmement précaires, ils se plaignent en revanche d'être déracinés de leur milieu de vie central pour être délocalisés loin du centre-ville et des infrastructures de transport. L'envoi de lettres de protestation aux hauts dirigeants du Parti est la forme classique d'expression du mécontentement sous l'ère stalinienne et Zubovich a souvent recours à ce type de sources afin de comprendre les effets des transformations urbaines sur les Moscovites.

Le décalage entre ce que l'historienne appelle le Moscou des plans, ville lisse et idéale des architectes et des ingénieurs, et le Moscou de l'ombre, ville réelle et vécue des Moscovites, parcourt le livre. Ainsi, le Plan de Moscou de 1949 était tiraillé entre deux directions inverses. D'un côté, il appelait à une construction massive de logements dans une ville connaissant une sérieuse pénurie 
d'appartements de qualité dans l'après-guerre. De l'autre, il sanctifiait la construction des gratte-ciels staliniens, dont la fonction principale n'était pas le logement de masse. Si certains abritaient des appartements, ceux-ci étaient réservés à l'élite intellectuelle soviétique, qui devait jouer du coude pour s'en approprier un. Bien que certains employés du chantier aient réclamé d'y être logés, puisque, après tout, c'était grâce à eux que les gratte-ciels existaient, leurs souhaits ne furent pas exaucés.

Pour ces ouvriers et ouvrières - comme les photos d'époque l'attestent, des femmes étaient employées sur les chantiers - la reconnaissance venait autrement. Leur travail était glorifié dans les médias soviétiques. Ils étaient comparés à des aviateurs : eux aussi permettaient à l'Union soviétique d'atteindre de nouveaux sommets. La métaphore de la construction était puissante. C'est à travers l'édification de ces immeubles monumentaux que l'État et ses sujets pouvaient se reconstruire après la guerre victorieuse, mais dévastatrice. Les milliers de prisonniers envoyés sur les chantiers de construction moscovites, bien que ne figurant pas dans les récits populaires, avaient eux aussi l'occasion de se reconstruire en participant à ces projets urbains grandioses.

La contradiction entre les besoins matériels de logement de la capitale et l'obsession stalinienne pour le monumentalisme puisant dans un vocabulaire architectural occidental — tout cela dans le contexte de la doctrine Ždanov dénonçant le libéralisme et l'impérialisme des mêmes occidentaux — finit par ressurgir après la mort de Stalin. Hruščev condamna dès 1954 les décorations inutiles et les projets grandioses, appelant plutôt les architectes et les ingénieurs à s'intéresser à l'efficacité dans la construction et à l'utilisation accrue de matériaux industriels et préfabriqués. C'est sous sa gouverne que s'accélérera finalement la périurbanisation de Moscou et la construction de logements d'inspiration moderniste dans les périphéries. Le monumentalisme des Sept Sœurs sera ensuite dénoncé par certains architectes soviétiques, mais ces gratte-ciels trônent toujours sur Moscou, à peine ombragés par les murs de verre des tours du nouveau quartier des affaires de Moskva-City.

En définitive, Moscow Monumental est une contribution majeure à l'histoire urbaine et à l'histoire soviétique. Sans nier l'importance performative des plans et des utopies, Zubovich analyse avec érudition et finesse les conséquences réelles et matérielles du monumentalisme stalinien sur les Moscovites ordinaires, dont les lettres de revendication nous permettent d'avoir une idée — biaisée, certes — de leurs aspirations. Il aurait été intéressant de s'arrêter un peu plus sur l'origine des matériaux de construction : d'où provenaient-ils ? Les pénuries matérielles importantes après la Seconde Guerre mondiale ont-elles freiné ou modifié les plans de construction? Mais ces préoccupations mineures ne viennent en rien diminuer l'apport de ce travail excellent.

Clarence Hatton-Proulx

INRS, Montréal

Sorbonne-Université, Paris 